\title{
Advances in the Prevention of Infection-Related Preterm Birth
}

\begin{abstract}
Ronald F. Lamont ${ }^{1,2 *}$
${ }^{1}$ Research Unit of Gynecology and Obstetrics, Department of Gynecology and Obstetrics, Institute of Clinical Research, Odense University Hospital, University of Southern Denmark, Odense, Denmark, ${ }^{2}$ Division of Surgery, University College London, London, UK
\end{abstract}

Infection-related preterm birth (PTB) is more common at early gestational ages and is associated with major neonatal mortality and morbidity. Abnormal genital tract microflora in early pregnancy predicts late miscarriage and early PTB. Accordingly, it is logical to consider antibiotics as an intervention. Unfortunately, the conclusions of systematic reviews and meta-analyses (SR\&MAs) carried out in an attempt to explain the confusion over the heterogeneity of individual studies are flawed by the fact that undue reliance was placed on studies which: (a) had a suboptimal choice of antibiotic (mainly metronidazole) or used antibiotics not recommended for the treatment of bacterial vaginosis (BV) or BV-related organisms; (b) used antibiotics too late in pregnancy to influence outcome (23-27 weeks); and (c) included women whose risk of PTB was not due to abnormal genital tract colonization and hence unlikely to respond to antibiotics. These risks included: (a) previous PTB of indeterminate etiology; (b) low weight/body mass index; or (c) detection of fetal fibronectin, ureaplasmas, Group B streptococcus or Trichomonas vaginalis). While individual studies have found benefit of antibiotic intervention for the prevention of PTB, in meta-analyses these effects have been negated by large methodologically flawed studies with negative results. As a result, many clinicians think that any antibiotic given at any time in pregnancy to any woman at risk of PTB will cause more harm than good. Recently, a more focused SR\&MA has demonstrated that antibiotics active against BV-related organisms, used in women whose risk of PTB is due to abnormal microflora, and used early in pregnancy before irreversible inflammatory damage has occurred, can reduce the rate of PTB. This review presents those data, the background and attempts to explain the confusion using new information from culture-independent molecular-based techniques. It also gives guidance on the structure of putative future antibiotic intervention studies.

Keywords: infection, antibiotics, bacterial vaginosis, preterm labour/labor, preterm birth

Abbreviations: AF, amniotic fluid; BMI, body mass index; BV, bacterial vaginosis; CDC, Centers for Disease Control and Prevention; CSAIDS, cytokine suppressive anti-inflammatory drugs; CVC, clindamycin vaginal cream; FDA, Food and drug Administration; GBS, group B streptococcus; HIV, human immunosuppressive virus; HPV, human papilloma virus; HSV, herpes simplex virus; IA, intra-amniotic; IL, interleukin; IV, intravenous; LPS, lipopolysaccharides; MMP, matrix metalloproteinases; PG, prostaglandin; PPROM, preterm prelabor rupture of the membranes; PTB, preterm birth; RCT, randomized controlled trial; SPTL, spontaneous preterm labor; SR\&MA, systematic review and meta-analysis.

Received: 16 January 2015 Accepted: 23 October 2015 Published: 16 November 2015 Preterm Birth 


\section{THE IMPORTANCE OF PRETERM BIRTH}

In high-income countries, preterm birth (PTB), particularly at early gestations, is the major cause of death and handicap in neonates (1-3). Babies born at 22, 24, and 26 completed weeks of gestation have an infant mortality rate of 54,21 , and $2 \%$, respectively, and a rate of survival without major morbidity at 365 days of $0.02,14.1$, and $45.9 \%$, respectively (2). Approximately $65 \%$ of babies born between 22 and 26 completed weeks of gestation will die on the labor ward or in the neonatal intensive care unit and at 30-month follow-up, around 50\% will be handicapped and in $50 \%$ of these, the handicap will be severe. Accordingly, at 2.5 years of age only $12-13 \%$ will be alive and intact (3). In the UK, the cost of hospital readmissions in the first five and 10 years of life is 20 times greater for those babies born before 28 completed weeks of gestation compared to those born after 37 completed weeks (4). In 2007, the Institute of Medicine calculated that the annual cost associated with PTB in the USA was $\$ 26.2$ billion comprising medical costs for the baby ( $\$ 16.9$ billion), labor and delivery costs for the mother ( $\$ 1.9$ billion), early intervention programs for children with disabilities and developmental delays from birth to age 3 years (\$611 million), special education services ( $\$ 1.1$ billion), and lost work and pay for those born preterm ( $\$ 5.7$ billion) (5). It has been demonstrated that between 23 and 26 completed weeks of gestation, each day of prolongation of pregnancy increases the survival rate by $3 \%(6)$.

\section{INFECTION AS A CAUSE OF PRETERM BIRTH}

Spontaneous preterm labor (SPTL) leading to PTB is now recognized as a syndrome caused by a number of pathological processes leading to activation of the common terminal pathway of parturition (7). The etiology of SPTL is multifactorial but there now exists abundant evidence that local or systemic infection or inflammation is a major cause, particularly of early PTB (8-10). This involves inter alia, prostaglandins (PGs), proinflammatory chemokines and cytokines, as well as pattern recognition receptors known as toll-like receptors $(11,12)$. In addition, the relationship between infection and PTB changes as pregnancy progresses. Infection in late PTB (34-36 weeks) is unusual but is present in most cases in which PTB occurs before 30 weeks gestation (13). In addition, the earlier in pregnancy at which PTB occurs, the more likely it is to be due to infection (14, 15). Between 26 and 34 completed weeks of gestation, women admitted in SPTL are more likely to have abnormal genital tract microflora and chorioamnionitis compared to women delivered electively at the same gestational age for feto-maternal indications (16-18). Compared with term birth, the prevalence of maternal endometritis, chorioamnionitis and neonatal infection is much more common following PTB $(10,13,19,20)$. The gestational age association of acute chorioamnionitis shows a dramatic reduction from $94.4 \%$ at $21-24$ weeks to $39.6 \%$ (25-28 weeks), $35.4 \%$ (29-32 weeks), $10.7 \%$ (33-36 weeks), and only $3.8 \%$ at $37-40$ weeks (21).

\section{THE PREDICTION OF INFECTION- RELATED PRETERM BIRTH}

As pregnancy progresses, the genital tract microflora becomes progressively more benign such that by term; the vaginal microflora poses no significant threat to the fetus as it passes through the birth canal (22). Although all births before 37 completed weeks of gestation are defined as preterm, PTB before 32 weeks gestation ( $2 \%$ of all births) accounts for most of the neonatal mortality and morbidity (23). Accordingly, if screening and treatment begins at gestations beyond 24 weeks, the opportunity to prevent late miscarriage and very early PTB is lost. The main cohort studies from Europe, North America, and Indonesia (24-33) and three case control studies from the USA, Sweden, and Australia (34-36) have used different methodologies to examine the association between abnormal genital tract microflora either in the form of bacterial vaginosis (BV) or the presence of BV-associated organisms and adverse outcomes of pregnancy. The majority of these studies show a statistically significant association between abnormal genital tract microflora and late miscarriage and PTB. Furthermore, the degree of risk is greater the earlier in pregnancy at which abnormal microflora was detected (24). A positive screening test for abnormal genital tract microflora at 26-32 weeks gestation is associated with a statistically significant 1.4- to 1.9-fold increased risk of PTB $(27,29-32)$. In contrast, a positive result from screening in the second trimester is associated with a 2.0- to 6.9-fold increased risk of an adverse outcome (25-28). In a longitudinal study of women in Indonesia, women with BV in early pregnancy had a $21 \%$ risk of an adverse outcome, compared to only $11 \%$ of those who developed the condition later in pregnancy (27).

\section{Abnormal Genital Tract Microflora}

Due to the polymicrobial nature of vaginal microflora, the definition of what is normal or abnormal genital tract microflora is very difficult. Normal vaginal microflora is assumed to be present in the absence of disease. Disease results from the interplay between microbial virulence, numerical dominance, and the innate and adaptive immune response of the host. Disease is assumed to be absent if the woman is asymptomatic, and there are no clinical signs of vaginal infectious morbidity. Abnormal vaginal microflora may occur (a) because of a sexually transmitted infection; (b) colonization by an organism which is not normally a constituent part of the vaginal microbial community such as Haemophilus influenzae, or Listeria monocytogenes; (c) due to increased virulence or overgrowth of an organism that is normally a constituent part of the vaginal microflora, e.g., Escherichia coli; or (d) BV.

\section{The Bacterial Vaginosis Syndrome}

Disordered vaginal microflora sometimes now referred to as "dysbiosis" is most commonly due to BV - a polymicrobial condition, characterized by a significant decrease in the quantity or quality of lactobacilli in association with a 1,000-fold increase in the number of other potentially pathogenic organisms such as Gardnerella vaginalis, Mycoplasma hominis, Mobiluncus species, and other anaerobic organisms. Since many of the organisms 
associated with BV are quite fastidious, and since BV is a quantitative rather than a qualitative change in vaginal microflora, qualitative or semiquantitative culture techniques are unhelpful for diagnosis. Accordingly, the diagnosis of BV requires quantification of vaginal microbiota (37). With the introduction of culture-independent techniques, more sensitive and specific ways of diagnosing BV may be developed (38-40). BV affects almost a third of women (41). In gynecological practice, BV has been found to be associated with the acquisition of STIs such as chlamydia, gonorrhea, trichomoniasis, and viral infections (HIV, HSV, and $\mathrm{HPV}$ ), plus a range of morbidities including postabortal sepsis, infertility, pelvic inflammatory disease, and posthysterectomy vaginal cuff infections. In pregnancy, BV has been associated with PTB, preterm prelabor rupture of the membranes (PPROM), early, late, and recurrent miscarriage, and postpartum endometritis (24). If BV is detected early in pregnancy, it is associated with a five to sevenfold increased risk of SPTL and PTB $(25,26)$. A longitudinal study in pregnancy has demonstrated that only $2 \%$ of women who did not have BV in the second trimester will develop BV by 34 weeks. In contrast, $50 \%$ of women who had BV in the second trimester will still have BV at 34 weeks (42).

\section{New Information from Culture-Independent, Molecular-Based Techniques}

Recent evidence from cultivation-independent molecular-based techniques has demonstrated that BV is not a single entity but a syndrome (the BV syndrome) of different sub-types with different etiologies, different microbial communities, and hence different responses to antibiotics and, in all likelihood, different subsequent phenotypical outcomes from normal term birth to late miscarriage, very early PTB, PPROM, or preterm stillbirth (38). Such new information clarifies why the etiology remains unknown, why the microbiology of BV differs from case to case, and why the response to antibiotics remains inconsistent. It would also explain why the phenotypic outcome of pregnancy differs from case to case, ranging from a normal outcome to a very early PTB or late miscarriage. A better understanding would help to limit the administration of antibiotics for the prevention of infection-related PTB to those antibiotics that are known to be effective in women with objective evidence of abnormal vaginal microflora and use these antibiotics early in pregnancy before inflammation and tissue damage has occurred (43).

\section{ANTIBIOTICS FOR THE PREVENTION OF INFECTION-RELATED PRETERM BIRTH}

This review reflects the use of prophylactic antibiotics used early in pregnancy for the prevention of PTB and does not cover the management of PPROM, which may be a cause, or a result of infection and probably a combination of the two. The literature pertaining to the use of antibiotics following PPROM is legion and so may be the subject of a separate review.

We know that abnormal vaginal colonization in early pregnancy is predictive of PTB $(24,25,27-36)$. Accordingly, it is logical to consider the use of antibiotics for the prevention of infection-related PTB. Unfortunately, antibiotic studies have chosen different: (a) risk groups; (b) diagnostic methods; (c) degrees of abnormal vaginal colonization; (d) antibiotic dose regimens and routes of administration; (e) women with different host susceptibilities and hence host response; (f) gestational age at time of treatment; (g) outcome parameters; and (h) definitions of success (44-62). Understandably, the results of such studies are conflicting. A number of systematic reviews and meta-analyses (SR\&MAs) of these studies have been conducted and updated (63-74). However, SR\&MAs are retrospective analyses of pooled data that are only as good as the quality of studies included (75). Due to the aforementioned limitations of the studies published to date, the conclusions derived from these SR\&MAs are also limited and should not be used to provide guidelines or make recommendations for the use or change of practice (75). Similarly, until recently, none of the SR\&MAs on the use of antibiotics for the prevention of infection-related PTB has simultaneously addressed the optimal choice of agent, the choice of patient, and the timing of intervention. If antibiotic intervention is to be successful in reducing the incidence of $\mathrm{PTB}$, these antibiotics (a) should be active against those organisms known to be associated with PTB, (b) should only be used in women with abnormal genital tract microflora, and (c) should be used early in pregnancy before infection and inflammation have had an opportunity to cause irreversible damage which will inevitably lead to SPTL and PTB.

\section{Choice of Antibiotic}

The Centers for Disease Control and Prevention (CDC) do not recommend erythromycin or coamoxiclav for the treatment of BV. Their recommendation is to use either metronidazole or clindamycin, orally or vaginally (76). Like macrolide antibiotics, clindamycin has anti-inflammatory properties (77-81) and has a broader range of activity against BV-related organisms such as species of Mobiluncus and the genital mycoplasmas (82-87). Metronidazole and other nitro-imidazoles are inactive in vitro against BV-associated organisms such as M. hominis, G. vaginalis, Ureaplasma urealyticum $(88,89)$, and Atopobium vaginae $(90,91)$. In addition, they have little or no activity against other aerobic organisms such as Staphylococcus aureus or species of Streptococci. However, metronidazole has a similar treatment success rate as clindamycin in vivo (76). This suggests one or both of two possible mechanisms. Firstly, in vivo, BV-related organisms may be sensitive to the hydroxy-metabolite of metronidazole. Alternatively and more likely, metronidazole acts indirectly by destroying anaerobes which provide nutrients to other BV related organisms such as $G$. vaginalis or A. vaginae (92). Molecular-based studies have indicated a far greater diversity of microorganisms associated with BV than has been evident from culture-dependent techniques (38). These organisms form different communities that may be anaerobe dominated or $G$. vaginalis and $A$. vaginae dominated. Other abnormal subtypes may be due to mixed organisms or perhaps due to a subtype caused by sexual transmission (38). Accordingly, it is possible that those sub-types of BV in which anaerobes are dominant are more successfully treated by metronidazole. In contrast, in other subtypes where anaerobic organisms are not dominant, metronidazole may be less effective. Finally, clindamycin may be active against both metronidazole-sensitive sub-types but also against 
a wider range of BV sub-types with different microbial communities. It should be noted that while M. hominis is extremely sensitive to clindamycin, U. urealyticum is only weakly sensitive to clindamycin $(87,93)$.

\section{Effect on Lactobacilli}

When comparing clindamycin with metronidazole, the case for metronidazole and against clindamycin is often given that metronidazole conserves vaginal lactobacilli, whereas clindamycin destroys them. However, phage virus colonization of lactobacilli is associated with BV, and it has been postulated that diet acquired phage viruses, may be induced to become lytic by a factor related to sexual activity, or alternatively that Lactobacillus phages may be directly inoculated into the vagina from sexual partners (94). If phage virus colonization of lactobacilli is present, metronidazole may be perpetuating rather than curing $\mathrm{BV}$, whereas the opposite would be true with clindamycin.

\section{PREMEVA1 Trial}

In 2013, an abstract presented orally to the Society for MaternalFetal Medicine was published on-line. http://dx.doi.org/10.1016/j. ajog.2013.10.036. The PREMEVA1 trial was a French multicentre randomized controlled trial comprising 2,869 low-risk women randomized to receive clindamycin or placebo before 15 weeks' gestation. In the placebo group, late abortion/very preterm spontaneous delivery rate (12-32 weeks) did not differ significantly between the clindamycin and placebo groups. Requests for details of the study have elicited no response. Accordingly, at the time of completion of this manuscript, no peer-reviewed, full-study report could be found on any of the appropriate search engines. This being the case, the risk of bias cannot be assessed and, until the details of the study are fully available, it is difficult to comment on the significance of the findings and these should not be used to influence guidelines.

\section{Route of Administration of Clindamycin}

The choice between oral clindamycin or clindamycin vaginal cream (CVC) to treat abnormal genital tract microflora/BV in pregnancy needs to be addressed. Vaginal administration is the most direct and efficient route of administration of antibiotic to the site of the heaviest bacterial load. In contrast, we know that $\mathrm{BV}$ is associated with subclinical endometritis (95). Accordingly, if vaginal microorganisms have already gained access to the choriodecidua, they may not be treatable by CVC, and systematic therapy may be necessary. To the authors knowledge, no study has studied the simultaneous combined use of CVC and oral clindamycin.

\section{The Potential for Newer Macrolide Antibiotics}

More data are now available on azithromycin and a new antibiotic, solithromycin, that may be considered candidate antibiotics in future intervention studies. In a SR\&MA, macrolides and clindamycin administered during the second trimester of pregnancy were associated with a reduction in the rate of PTB (96). Second trimester metronidazole used alone was associated with an increased risk of PTB in a high-risk population. Like many other SR\&MAs, studies were included where the risk of PTB was positive fetal fibronectin, urogenital mycoplasma infection, previous PTB of unqualified phenotype, or prepregnancy weight of $<50 \mathrm{~kg}$. In addition, while azithromycin and clarithromycin were included in the search, the only macrolide included was erythromycin (96). In a RCT of interconceptional antibiotics to prevent $\mathrm{PTB}$, neither azithromycin nor metronidazole was of any benefit in reducing the subsequent rate of PTB (97).

Two recent studies from Malawi tested the effect of prophylactic azithromycin on the subsequent rate of PTB. In a high-risk population, routine prophylaxis with azithromycin showed no benefit, but this population was unselected (high risk of poor pregnancy outcome but not specifically PTB), and no objective evidence of infection-related risk of PTB was sought (98). Also in Malawi, a RCT of intermittent treatment of maternal malaria and reproductive tract infection with monthly sulfadoxinepyrimethamine plus two doses of azithromycin was associated with a significant reduction in PTB and low birth weight (99).

Solithromycin is a new antibiotic that is highly potent against ureaplasmas and mycoplasmas and other antibiotic resistant organisms. In an animal study, combined intra-amniotic (IA) and intravenous administration of solithromycin resulted in effective concentrations of solithromycin in amniotic fluid (AF) and maternal and fetal plasma, leading the authors to conclude that solithromycin may have promise in future for the prevention of PTB (100). Subsequent studies showed that a 4-day course of solithromycin eradicated IA Ureaplasma parvum infection in the same sheep model (101).

\section{Choice of Patient}

Women with BV (Nugent score 7-10) respond better to clindamycin than women with intermediate microflora (Nugent score 4-6). Accordingly, prophylactic antibiotics to prevent infection-related PTB should only be given to women with objective evidence of abnormal vaginal colonization such as BV (37). Without such evidence, treatment may disrupt, rather than treat, abnormal microflora. In many antibiotic intervention studies, the indication for administration of prophylactic antibiotics was previous PTB. There is no doubt that previous PTB is a known risk factor for subsequent PTB $(102,103)$. However, a previous PTB may have been for feto-maternal indications, such as antepartum hemorrhage and fulminating pre-eclampsia. Such indications would not place a subsequent pregnancy at risk of infection-related PTB and consequently are unlikely to benefit from antibiotic prophylaxis. Such studies (104), have been erroneously cited as evidence that antibiotics have no role in the prevention of PTB (105). Only a small portion of such women (even those with BV) may be at risk for PTB. Better diagnostic or predictive methods are required to improve our ability to identify those women who would be most likely to benefit from treatment with antibiotics.

\section{Pharmacogenetics}

Pharmacogenetics is also an important consideration (106). Metronidazole used in mainly Black or Hispanic women in North America has not shown benefit (52). In contrast, in predominantly White North European women, five studies using clindamycin have shown benefit (43). Black or Hispanic women may have a genetic predisposition to mount a damaging 
inflammatory response to the challenge of $\mathrm{BV}$, while predominantly white Northern European women do not. Alternatively, in predominantly white Northern European women, the inflammatory response may be sufficiently less rigorous to allow time for antibiotic therapy to be of benefit. Finally, it may be that some women with a prior PTB have a genetically non-infectious risk of PTB under which circumstances their propensity to deliver preterm will exist with or without BV and hence would not be expected to respond to antibiotic treatment. These studies and the findings of racial differences in the vaginal microbiome highlight the importance of tailoring antibiotic treatment approaches for different racial groups and controlling for race in clinical trials.

\section{Treatment of Symptomatic or Asymptomatic Pregnant Women with BV}

Symptomatic pregnant women with BV should be treated even if they are at otherwise low risk of PTB. The management of asymptomatic women with BV who do not have other risk factors such as a previous BV-related PTB is less well accepted. Since BV is an independent risk factor for PTB, one could argue that any woman with BV (symptomatic or asymptomatic) is at a significant twofold increased risk of PTB, if BV is detected at or beyond 24 completed weeks of gestation. This is the same risk associated with smoking which is considered significant enough to merit intervention. In contrast, if BV is detected before 16 weeks gestation, there is a five to sevenfold increased risk of PTB (see the Section on The Prediction of Infection-Related Preterm Birth). If one relies on previous PTB as a risk factor for subsequent PTB in women with $\mathrm{BV}$, it is essential to record the phenotype of that previous $\mathrm{PTB}$. If the previous $\mathrm{PTB}$ was iatrogenic, because of twins, APH, or pregnancy-induced hypertension/preeclampsia, it may not be relevant in women with BV. Similarly, if the previous PTB was unexplained apart from a maternal weight $<50 \mathrm{~kg}$ or a $\mathrm{BMI}<18 \mathrm{~kg} / \mathrm{m}^{2}$ then the detection of BV may be irrelevant. As more information becomes available from molecular-based, cultivation-independent techniques, the identification of sub-types of $\mathrm{BV}$, the different etiologies of each, the different microbiology, the different response to antibiotics, and the different phenotypic outcomes may address this concern.

\section{Timing of Antibiotics}

Abnormal genital tract microflora in early pregnancy, even if this reverts to normal, is still associated with late miscarriage and PTB (44) suggesting that whatever damage is done by infection and inflammation, this occurs early and persists (44, 107-113). If antibiotics are used late in pregnancy when inflammatory tissue damage may have already occurred, and there are already irreversible changes in the cervix, myometrium, decidua, placenta, and extraplacental membranes, then antibiotics are unlikely to be of benefit. Accordingly, concern has been expressed that under these circumstances, antibiotics may cause more harm than good (114-120). Hence, it may be argued that antibiotics should be used early in pregnancy before infection/inflammation can cause irreversible damage that ultimately leads to SPTL and PTB. In their recommendations for the treatment of BV in pregnancy, the CDC treatment guidelines advise the use of oral or vaginal metronidazole or oral clindamycin (76). However, it was noted that the late administration of CVC up to 32 weeks gestation was associated with subsequent adverse outcomes, such as low birth weight and neonatal infection $(28,48,51)$. As a result, the guidelines recommend that CVC should only be used in the first half of pregnancy (76).

\section{Gene-Environmental Interaction}

Many diseases like PTB are due to a combination of genetic susceptibility and environmental exposure. A woman may have the environmental exposure (BV), but if she does not have the genetic susceptibility (gene polymorphism) to mount a damaging inflammatory response then little harm may occur. Conversely, a woman may possess the gene polymorphism to mount a damaging inflammatory response, but if she does not have environmental exposure (BV) then damage may not occur. However, when both susceptibility and exposure are present, the risk of an adverse outcome will be increased, and this is referred to as the gene-environmental interaction (121). Abnormal vaginal microflora or infection leads to adherence, invasion, and host inflammatory response. That response may be appropriate resulting in tissue repair and healing. Alternatively, the response may be exaggerated (hyper-response) resulting in tissue damage from increased production and release of proinflammatory cytokines. Conversely, the response may be inadequate (hyporesponse) leading to overwhelming infection. Both a hyper-response and a hypo-response may result in mortality and morbidity due to tissue damage. If antibiotics are used late in this process, it may not be possible to prevent irreversible tissue damage, morbidity, and mortality. In contrast, if antibiotics are used early, before tissue damage occurs, this damage might be prevented. Accordingly, the earlier the gestational age at which clindamycin is administered to women with objective evidence of risk of infection-related PTB, the more likely it is to be able to demonstrate a reduction in the rate of PTB (43).

\section{Potential for the Use of Anti-inflammatory Agents as Adjunctive Treatment}

The potential for adding to antibiotics an anti-inflammatory agent which targets the NF- $\mathrm{BB}$ and p38 MAPK (cytokine suppressive anti-inflammatory drugs [CSAIDs]) that block cytokine signaling for the prevention and treatment of inflammation-induced PTB shows promise and has been comprehensively reviewed elsewhere (122). In an ovine model, IA administration of a single dose of CSAID suppressed the lipopolysaccharide-induced IA inflammatory response with minimal fetal effects (123). Several animal model studies have shown additional benefit of antibiotic cotreatment with anti-inflammatory agents. In the rhesus monkey, following IA inoculation of U. parvum, azithromycin plus dexamethasone and indomethacin was able to prolong pregnancy and prevent advanced fetal lung injury (124). Similarly, to determine whether treatment with ampicillin/dexamethasone/indomethacin (AMP/DEX/INDO) delayed PTB induced by IA Group $B$ streptococcus (GBS) inoculation in rhesus monkeys, ampicillin alone eradicated GBS but uterine activity, AF cytokines, PGs, and matrix metalloprotein (MMP)-9 remained elevated. In contrast, 
the combination of AMP/DEX/INDO suppressed interleukin$1 \beta$, TNF- $\alpha, \mathrm{PGE}_{2}$, and $\mathrm{PGF}_{2 \alpha}$ but did not alter MMP expression or chorioamnionitis. The combination of AMP/DEX/INDO suppressed inflammation and significantly prolonged gestation (125).

\section{Rescreening and Retreating with Antibiotics}

In many antibiotic intervention studies there has been inconsistency of rescreening and retreatment in which persistent or recurrent BV occurs in 10-30\% (43). Using stringent diagnostic criteria (BV on Nugent score together with all four elements of Amsel's clinical composite criteria), $70.8 \%$ of women who received CVC were cured/improved at 20-24 days post-treatment compared to only $12 \%$ in the placebo group. Recurrence rates in those CVC patients successfully treated were $\sim 6 \%$ at 6 weeks postbaseline and $10 \%$ at $28-34$ weeks. Of the $29.2 \%$ of women who failed to respond to the first 3-day course of CVC and who were therefore retreated with a 7 -day course of CVC, $32.6 \%$ and $51.2 \%$ were cured/improved at $20-24$ days postretreatment and at 28-34 weeks gestation, respectively (126). Accordingly, rescreening and retreating in pregnancy may be helpful since an initial course of CVC cured or improved BV in $88 \%$ of women, and a second course some 3-6 weeks later was still able to cure or improve BV in 50\% of those who still had the condition (127).

\section{CRITICAL REVIEW OF THE LITERATURE ON THE USE OF ANTIBIOTICS TO PREVENT INFECTION-RELATED PRETERM BIRTH}

As discussed earlier, the majority of the SR\&MA that consider the use of antibiotics for the prevention of PTB inappropriately merged clindamycin and metronidazole studies together rather than considering them separately. Those studies that initially considered clindamycin and metronidazole studies separately then erred by combining the two antibiotics when considering the gestational age at treatment $(63,66,74)$. While the majority of studies included in the SR\&MA comprised women with objective evidence of $\mathrm{BV}$, two meta-analyses included studies where the risk-status or entry criteria was measured by other parameters unrelated to BV. These included parameters, such as positive fetal fibronectin test, previous PTB, and detection of GBS, $U$. urealyticum, or trichomonas $(66,74)$. Using these SR\&MAs, it can be concluded that if inappropriate antibiotics are used at late gestations, in women without objective evidence of abnormal vaginal bacterial colonization, there is no benefit with respect to the prevention of infection-related PTB. However, concerns have been expressed that if these SR\&MAs are not interpreted carefully, they will be erroneously cited as evidence that any antibiotic, given to any pregnant woman, at any gestational age will be unhelpful in preventing PTB. For this interpretation, caution has been urged (114-120, 128-130). Two large studies are regularly cited in SR\&MA as evidence that antibiotics are of no benefit for the prevention of PTB: the National Institutes for Child Health and Human Development (NICHD)/Maternal Fetal Medicine
Network Units (MFMU) study (52) and the ORACLE II study $(131,132)$. Despite their faults (see below), these studies markedly outweigh all other studies in SR\&MA and hence strongly influence conclusions.

\section{The NICHD/MFMU (2000) Study}

This study screened 29,626 women (52) of which 6,540 were positive solely for BV without other conditions, such as trichomoniasis. From these, the recruitment was low with only 1,936 (29.6\%) randomized to receive either metronidazole or placebo. Of the 4,604 exclusions, 999 were excluded for reasons recorded as "other." Most SR\&MAs classify this study as having been in a "low-risk population" yet $85 \%$ of the population was either Black or Hispanic. As a part of the methodology, up to 8 weeks could elapse between screening and initiation of treatment. During this delay, the grade of microflora on Gram stain changed in $25 \%$ of women (115). Metronidazole was administered as a once only $2 \mathrm{~g}$ oral dose and unsurprisingly, vomiting occurred in a high percentage of women. Under such circumstances, the $2 \mathrm{~g}$ oral dose was repeated 2 days later. With no objective measure of compliance, such as metronidazole blood levels, the number of women who took the repeat course remains undocumented. Importantly, there was an inexplicable $37 \%$ placebo effect while $\mathrm{BV}$ remained in $22 \%$ of the metronidazole group and $63 \%$ of the placebo group at 1 month. This suggests confounding by factors, such as a lack of effectiveness of metronidazole in the treatment group or spontaneous resolution in the placebo group. Finally, treatment was started late in pregnancy with $44 \%$ treated after 20 weeks gestation, and no women were treated before 16 weeks gestation.

\section{ORACLE II Study}

The ORACLE II trial is commonly cited as evidence that antibiotic treatment does not prevent PTB. More accurately, the ORACLE II trial should be cited as demonstrating that if inappropriate antibiotics are given to women too late in pregnancy with no objective evidence of abnormal vaginal microflora then they are ineffective in preventing infection-related PTB. Accordingly, in any SR\&MAs related to the use of antibiotics to prevent infectionrelated PTB, the Oracle II study should be excluded; sadly, this is not the case and due to the numbers involved the study has a strong weighting such that the positive results of other studies are negated. Erythromycin and coamoxiclav were used in this study (132) because of the perceived importance of Ureaplasmas in neonatal infectious morbidity (133), but neither is recommended for the treatment of BV (76). It is notable that erythromycin, while being effective against Ureaplasma spp., exhibits minimal passage across the placenta and hence does not reach effective concentrations in AF. Hence it is not effective in eradicating intrauterine Ureaplasma infections. Women with known infections were excluded, and the trial protocol required no objective evidence of abnormal vaginal colonization for the diagnosis of BV (37). Without objective evidence of abnormal vaginal microflora, at least $60 \%$ and probably more at this late gestation were not in infection-related SPTL. There are also serious concerns about the accuracy of diagnosis of SPTL. Only 50\% of cases required tocolytics and around $90 \%$ of women were still undelivered after 
48 h. Approximately $85 \%$ of women remained undelivered by 7 days and the mean gestational age at delivery was 38 weeks. The timing of administration of antibiotics was also questioned since the intervention occurred after SPTL had begun. Finally, in the 7-year follow-up report of the ORACLE II study (131), the assessment of cerebral palsy has been questioned. The assessment only applied to the two-thirds of cases that were recruited from the UK rather than the Republic of Ireland, and the assessment of cerebral palsy was based upon telephone calls to the parents, and in some cases, parent completed postal questionnaires rather than an objective, structured neurobehavioral assessment by skilled healthcare professionals.

\section{Cochrane Systematic Review (Updated 2013)}

The recently updated Cochrane Review $(63,74)$ is already being cited as evidence that antibiotics are unhelpful for the prevention of PTB. The updated review (74) is extensive and contains data from 21 trials and reports 57 different analyses. These numbers are necessary because the included studies used different risk groups, diagnostic methods, degrees of abnormal microflora, antibiotic dose regimens and routes of administration, host susceptibilities, host response, gestational age at time of treatment, outcome parameters, and definitions of success $(44-53,55-58)$ resulting in different results. However, in contrast to the systematic review reported below (43), the Cochrane Review (74) includes studies which used antibiotics that are not recommended for the treatment of BV and importantly did not consider the effect of pharmacogenetics (106) as outlined in the Section above "Choice of patient." In addition, the review included women with a previous PTB of non-infectious etiology. It did not differentiate between clindamycin and metronidazole when assessing the benefit of treatment before 20 weeks gestation. The review selected studies of pregnant women with either "BV" or "intermediate microflora" without considering that these are different entities with differing rates of response to antibiotics (134). Finally, the review did not include recent evidence of the benefit of rescreening and retreating BV in pregnancy (127) and the title of the Review was "the treatment of bacterial vaginosis in pregnancy" and should not have been used to comment on the prevention of preterm birth.

\section{AJOG Systematic Review 2011}

To address the deficiencies of existing SR\&MA with respect to the optimal choice of agent, the choice of patient, and the timing of intervention, we performed a SR\&MA of clindamycin use before 22 weeks gestation in women with abnormal genital tract microflora (43). The hypothesis of the review was that previous SR\&MA on the use of antibiotics used prophylactically for the prevention of PTB or their individual studies were flawed by the fact that undue reliance was placed on studies in which suboptimal antibiotics (mainly metronidazole) were used. They were also flawed by the fact that antibiotics were used too late in pregnancy to influence outcome (23-27 weeks gestation) and used in women whose risk of PTB was not due to BV but due to some other markers not directly related to infection. Conversely, the hypothesis of the SM\&MA was that antibiotics that are active against BV or
BV-related organisms that are appropriately used in women whose risk of PTB is due to abnormal genital tract colonization and that are administered early in pregnancy before irreversible inflammatory damage occurs can reduce the rate of PTB. The primary outcome of the studies included in this SR\&MA was spontaneous $\mathrm{PTB}$ at $<37$ completed weeks gestation and late miscarriage. These were chosen because they were used in most meta-analyses that evaluated preventative strategies for PTB. In the meta-analysis, the RR for delivery <33 weeks was 0.44 (95\% CI: 0.41-1.41; nine versus four cases), but due to the low numbers this was not statistically significant. Although the reduction was consistent with the beneficial effect of clindamycin seen in the later gestational age groups, further research is required to confirm efficacy at lower gestations. The SR\&MA demonstrated that when clindamycin was compared to controls, administration before 22 weeks gestation to women with objective evidence of abnormal genital tract microflora was associated with a significant reduction in the rates of PTB and late miscarriage by 40 and $80 \%$, respectively.

\section{Secondary Outcome Variables}

The secondary outcome variables demonstrated that of those infants born preterm, low birth weight occurred in $20 \%$ of those who received clindamycin compared to $80 \%$ of those who received no treatment $(P<0.009)$. There was also a 32.5-day difference in the mean prolongation of pregnancy in favor of clindamycin compared with no treatment $(P<0.024)(62)$. In women with the highest Nugent Score of 10, late miscarriage and PTB occurred in 5.4\% of those who received clindamycin compared to $35.7 \%$ of those who received placebo (60). Finally, the rate of late miscarriage or PTB was $28 \%$ in those women with persistent BV compared to $10 \%$ in those in whom $\mathrm{BV}$ was cured $(\mathrm{OR}=2.9 ; 95 \% \mathrm{CI}=1.3-5.2)$, and the rate of late miscarriage or PTB was $15 \%$ in women with cured but recurrent BV, compared to only $2 \%$ in those women whose BV was cured with no recurrence $(\mathrm{OR}=9.3 ; 95 \% \mathrm{CI}=1.6-53.5)(54)$.

\section{SAFETY OF AND RESISTANCE TO ANTIBIOTICS IN PREGNANCY}

The safety of antimicrobials in pregnancy has recently been reviewed (135). A common response to the case for antibiotic use to prevent infection-related PTB is that we already use antibiotics too frequently in pregnancy. However, few can cite local/personal audit of such practice. Accordingly, we reported a large, population-based study comprising nearly 1 million Danish women which demonstrated that $>40 \%$ received antimicrobials at some stage during pregnancy (136). We felt that this might be an underestimate because Denmark, like other Nordic countries, is cautious about the use of antibiotics in pregnancy. In addition, the Registry used included only antibiotics obtained by prescription in the community. Our response would be that by employing a more focused approach to the use of antibiotics for the prevention of infection-related PTB we would, in effect, be reducing the indiscriminate use of antibiotics already demonstrated. The development and introduction of new antibiotics has declined markedly and drug-resistant bacteria are more common in hospitals and the community. In 2013, a report by the CDC 
reported that $>2,000,000$ people each year suffer from antibiotic resistant infections and $>23,000$ die as a result. Unfortunately, the number of new drugs to replace ineffective antibiotics is not adequate to meet current needs, and many major pharmaceutical companies have abandoned development of new antibiotics, focusing instead on new, long-term medications, such as statins and antihypertensives that produce greater profits. As an incentive for manufacturers to develop new antibiotics, in 2012, the Generating Antibiotic Incentives Now (GAIN) legislation was signed into US law as a part of the FDA Safety and Innovation Act. This legislation extends by 5 years the exclusivity period during which time those antibiotics that treat serious or life-threatening infections can be sold without generic competition. Drugs that fall under the GAIN provisions receive fast track and priority review status and undergo an expedited regulatory approval process with the FDA (137).

\section{Neonatal Gut Microbiome and Atopic Disease}

New information from The Human Microbiome Project using cultivation-independent, molecular-based techniques has revolutionized our understanding of the vaginal microbiome in pregnancy and the non-pregnant state (38). The immune system is primed in utero and modified after birth. Accordingly, the use of antibiotics during pregnancy or the neonatal period may cause disruption of the developing neonatal gut microbiome, resulting in a failure of maturation of the immune response and the subsequent development of asthma, allergy, and atopic disease (138-141). This has led to new initiatives such as the Neomune Project publicly funded by the Danish Council for Strategic Research whose objective is to develop new diet and gut microflora treatments for new born infants.

\section{EVIDENCE-BASED MEDICINE}

Guidelines issued by professional bodies, such as the Royal College of Obstetricians and Gynecologists, use a systematically developed standardized methodology (http://www.rcog.org. uk/guidelines) and a standardized grading scheme for the classification of evidence levels and grades of recommendations. Other organizations or governing bodies that produce guidelines use very similar methodology and schemes. The highest classification of evidence is $1++$, which is defined as "high-quality meta-analyses, systematic reviews of randomized controlled trials or randomized controlled trials with a very low risk of bias." The highest grade of recommendation is A which is defined as "At least one meta-analysis, systematic review or randomized controlled trial rated as $1++$ and directly applicable to the target population; or a systematic review of randomized controlled trials or a body of evidence consisting principally of studies rated as $1+$ directly applicable to the target population and demonstrating overall consistency of results." Those who provide guidelines and recommendations base these on some SR\&MAs of some RCTs as a result of which they may claim to be "evidence based." SR\&MAs are only as good as those studies included and if the questions asked about the populations, interventions, and outcomes are wrong or misdirected they should not be used to make recommendations or provide clinical guidelines (75). The Cochrane database is often the default of many clinicians looking for information, yet Cochrane is not without its faults, particularly in the area of PTB (142). Most SR\&MAs of antibiotics for the prevention of PTB (Cochrane or otherwise) ask the question "In women at risk of PTB (population), do antibiotics (intervention) reduce the rate of PTB (outcome)." It is not surprising, therefore, that the updated Cochrane review of 2013 (74) contained data from 21 trials and required 57 different analyses because the included studies used different risk groups, diagnostic methods, degrees of abnormal microflora, antibiotic dose regimens and routes of administration, host susceptibilities, host response, gestational age at time of treatment, outcome parameters, and definitions of success (44-53, 55-58) resulting in different results. In contrast to other SR\&MAs, in the AJOG SR\&MA (43), the question was much more focused: "In pregnant women at risk of PTB of infectious etiology (population) does clindamycin administered before 22 weeks gestation (intervention) reduce the rate of PTB or late miscarriage (outcome)."

\section{FUTURE RESEARCH}

Even if the evidence based data is insufficient for some, they must at least accept that clinical equipoise exists (the ethical basis for medical research that involves assigning patients to different treatment arms of a clinical trial) and support a definitive randomized controlled trial. The choice of antibiotics (a) should be active against those organisms known to be associated with PTB, (b) should only be used in women with abnormal genital tract microflora, and (c) should be used early in pregnancy before infection and inflammation can cause irreversible tissue damage which will inevitably lead to SPTL and PTB. Such a study should contain genomic, transcriptomic, proteomic, and metabolomic studies to assess the vaginal microbiome, the vaginal milieu created by different microbiomic communities, and the host response of the individual to each sub-type of microbiome and milieu. PTB per se is only a surrogate for neonatal outcome. Detailed neonatal outcome data with appropriate long-term follow-up as well as the number of days gained from treatment to delivery should be the primary outcome parameters. Finally, different phenotypical outcomes of SPTL and PTB, such as late miscarriage, extreme PTB around the limits of viability, PPROM, late PTB, preterm stillbirth, and SPTL with intact membranes with or without vaginal bleeding should be considered. This is because the combination of different vaginal microbial communities, different vaginal milieu, and different host response may result in a range of phenotypic outcomes from normal term delivery to preterm stillbirth or severe morbidity associated with extremely premature birth.

\section{CONCLUSION}

The earlier in pregnancy at which PTB occurs, the more likely this is to be due to infection (14). The earlier in pregnancy at which abnormal genital tract colonization is detected, the greater 
is the risk of an adverse outcome like late miscarriage or PTB (24). Abnormal vaginal microflora in early pregnancy, even if this resolves, is still associated with an adverse outcome (44) suggesting that whatever damage is caused by infection, this occurs early and persists. Accordingly, if antibiotics are to be used to prevent infection-related PTB these should be administered early. New evidence from molecular-based culture-independent studies of the vaginal microbiome (38) indicates that across the range of different microbial communities or sub-types of BV the bacteria detected are more likely to respond to clindamycin than metronidazole. Finally, treatment on the basis of the previous PTB should be predicated by some measure of infective etiology. Antibiotic treatment on the basis of previous PTB of unknown etiology or other risk factors for PTB unrelated to abnormal genital tract microflora should be discouraged. While individual studies have

\section{REFERENCES}

1. March of Dimes Foundation. March of Dimes White Paper on Preterm Birth: The Global and Regional Toll (2009) [updated 2009 Dec 16]. Available from: https://www.sheffield.ac.uk/polopoly_fs/1.85389!/file/March-of-Dimes-Preterm-Birth-White-Paper.pdf

2. Fellman V, Hellstrom-Westas L, Norman M, Westgren M, Kallen K, Lagercrantz $\mathrm{H}$, et al. One-year survival of extremely preterm infants after active perinatal care in Sweden. JAMA (2009) 301(21):2225-33. doi:10.1001/ jama.2009.771

3. Costeloe K, Hennessy E, Gibson AT, Marlow N, Wilkinson AR. The EPICure study: outcomes to discharge from hospital for infants born at the threshold of viability. Pediatrics (2000) 106(4):659-71. doi:10.1542/peds.106.4.659

4. Petrou S, Abangma G, Johnson S, Wolke D, Marlow N. Costs and health utilities associated with extremely preterm birth: evidence from the EPICure study. Value Health (2009) 12:1124-34. doi:10.1111/j.1524-4733.2009.00580.x

5. Institute of Medicine. Preterm Birth: Causes, Consequences, and Prevention (2006) [updated 2009 Dec 16]. Available from: http://www.marchofdimes. com/prematurity/index_about_10734.asp

6. Finnstrom O, Olausson PO, Sedin G, Serenius F, Svenningsen N, Thiringer $\mathrm{K}$, et al. The Swedish national prospective study on extremely low birthweight (ELBW) infants. Incidence, mortality, morbidity and survival in relation to level of care. Acta Paediatr (1997) 86(5):503-11. doi:10.111 1/j.1651-2227.1997.tb08921.x

7. Romero R, Espinoza J, Mazor M, Chaiworapongsa T. The preterm parturition syndrome. In: Critchley H, Bennett P, Thornton S, editors. Preterm Birth. London: RCOG Press (2004). p. 28-60.

8. Fidel P, Ghezzi F, Romero R, Chaiworapongsa T, Espinoza J, Cutright J, et al. The effect of antibiotic therapy on intrauterine infection-induced preterm parturition in rabbits. J Matern Fetal Neonatal Med (2003) 14(1):57-64. doi:10.1080/jmf.14.1.57.64

9. Fidel PL Jr, Romero R, Wolf N, Cutright J, Ramirez M, Araneda H, et al. Systemic and local cytokine profiles in endotoxin-induced preterm parturition in mice. Am J Obstet Gynecol (1994) 170(5 Pt 1):1467-75. doi:10.1016/ S0002-9378(94)70180-6

10. Gomez R, Ghezzi F, Romero R, Munoz H, Tolosa JE, Rojas I. Premature labor and intra-amniotic infection. Clinical aspects and role of the cytokines in diagnosis and pathophysiology. Clin Perinatol (1995) 22(2):281-342.

11. Gomez R, Romero R, Mazor M, Ghezzi F, David C, Yoon BH. Role of infection in preterm labor and delivery. In: Elder MG, Romero R, Lamont RF, editors. Preterm Labor. New York, NY: Churchill Livingstone (1997). p. 85-125.

12. Hirsch E, Wang $\mathrm{H}$. The molecular pathophysiology of bacterially induced preterm labor: insights from the murine model. J Soc Gynecol Investig (2005) 12(3):145-55. doi:10.1016/j.jsgi.2005.01.007

13. Goldenberg RL, Hauth JC, Andrews WW. Intrauterine infection and preterm delivery. N Engl J Med (2000) 342(20):1500-7. doi:10.1056/ NEJM200005183422007

14. Seo K, McGregor JA, French JI. Preterm birth is associated with increased risk of maternal and neonatal infection. Obstet Gynecol (1992) 79(1):75-80. found benefit of antibiotic intervention for the prevention of PTB, in meta-analyses, these effects have been negated by large methodologically flawed studies with negative results. While (rightly) SR\&MAs of efficacy focus on primary outcome parameters, the benefits associated with secondary outcomes are important and should not be ignored (vide supra Secondary outcomes) (43). At worst, equipoise exists with respect to the early use of clindamycin for the prevention of infection-related PTB. If a further, hopefully definitive trial is deemed necessary, this should be of a design and contains molecular omic data which will give a greater understanding of the underlying systems biology and mechanisms involved so that the same mistakes of previous flawed studies are not repeated. In the meantime, the use of antibiotics in pregnancy for the prevention of PTB should be restricted to those who are most likely to benefit.

15. Shim SS, Romero R, Hong JS, Park CW, Jun JK, Kim BI, et al. Clinical significance of intra-amniotic inflammation in patients with preterm premature rupture of membranes. Am J Obstet Gynecol (2004) 191(4):1339-45. doi:10.1016/j.ajog.2004.10.268

16. Lamont RF, Newman MJ, Dunlop PD, Elder MG. The use of high vaginal, endocervical and rectal swabs in the diagnosis of genital infection in association with pre-term labour. Br J Clin Pract (1988) 42(4):146-9.

17. Lamont RF, Taylor-Robinson D, Wigglesworth JS, Furr PM, Evans RT, Elder MG. The role of mycoplasmas, ureaplasmas and chlamydiae in the genital tract of women presenting in spontaneous early preterm labour. J Med Microbiol (1987) 24(3):253-7. doi:10.1099/00222615-24-3-253

18. Lamont RF, Taylor-Robinson D, Newman M, Wigglesworth J, Elder MG. Spontaneous early preterm labour associated with abnormal genital bacterial colonization. Br J Obstet Gynaecol (1986) 93(8):804-10. doi:10.111 1/j.1471-0528.1986.tb07987.x

19. Romero R, Sepulveda W, Baumann P, Yoon BH, Brandt F, Gomez R, et al. The preterm labor syndrome: biochemical, cytologic, immunologic, pathologic, microbiologic, and clinical evidence that preterm labor is a heterogeneous disease. Am J Obstet Gynecol (1993) 168(1 Pt 2):287.

20. DiGiulio DB, Romero R, Amogan HP, Kusanovic JP, Bik EM, Gotsch F, et al. Microbial prevalence, diversity and abundance in amniotic fluid during preterm labor: a molecular and culture-based investigation. PLoS One (2008) 3(8):e3056. doi:10.1371/journal.pone.0003056

21. Russel R. Inflammatory lesions of the human placenta. I. Clinical significance of acute chorioamnionitis. Am J Diagn Gynecol Obstet (1979) 1(2):127-37.

22. Goplerud CP, Ohm MJ, Galask RP. Aerobic and anaerobic flora of the cervix during pregnancy and the puerperium. Am J Obstet Gynecol (1976) 126(7):858-68.

23. Goldenberg RL, Rouse DJ. Prevention of premature birth. N Engl J Med (1998) 339(5):313-20. doi:10.1056/NEJM199807303390506

24. Lamont RF. Bacterial vaginosis. In: Critchley H, Bennett P, Thornton S, editors. Preterm Birth. London: RCOG Press (2004). p. 163-80.

25. Hay PE, Lamont RF, Taylor-Robinson D, Morgan DJ, Ison C, Pearson J. Abnormal bacterial colonisation of the genital tract and subsequent preterm delivery and late miscarriage. BMJ (1994) 308(6924):295-8. doi:10.1136/ bmj.308.6924.295

26. Kurki T, Sivonen A, Renkonen OV, Savia E, Ylikorkala O. Bacterial vaginosis in early pregnancy and pregnancy outcome. Obstet Gynecol (1992) 80(2):173-7.

27. Riduan JM, Hillier SL, Utomo B, Wiknjosastro G, Linnan M, Kandun $\mathrm{N}$. Bacterial vaginosis and prematurity in Indonesia: association in early and late pregnancy. Am J Obstet Gynecol (1993) 169(1):175-8. doi:10.1016/0002-9378(93)90157-E

28. McGregor JA, French JI, Jones W, Milligan K, McKinney PJ, Patterson E, et al. Bacterial vaginosis is associated with prematurity and vaginal fluid mucinase and sialidase: results of a controlled trial of topical clindamycin cream 1966. Am J Obstet Gynecol (1994) 170(4):1048-59. doi:10.1016/ S0002-9378(94)70098-2 
29. Hillier SL, Nugent RP, Eschenbach DA, Krohn MA, Gibbs RS, Martin DH, et al. Association between bacterial vaginosis and preterm delivery of a lowbirth-weight infant. The Vaginal Infections and Prematurity Study Group. N Engl J Med (1995) 333(26):1737-42. doi:10.1056/NEJM199512283332604

30. Meis PJ, Goldenberg RL, Mercer B, Moawad A, Das A, McNellis D, et al. The preterm prediction study: significance of vaginal infections. National Institute of Child Health and Human Development Maternal-Fetal Medicine Units Network. Am J Obstet Gynecol (1995) 173(4):1231-5. doi:10.1016/0002-9378(95)91360-2

31. Gravett MG, Nelson HP, DeRouen T, Critchlow C, Eschenbach DA, Holmes KK. Independent associations of bacterial vaginosis and Chlamydia trachomatis infection with adverse pregnancy outcome 1969. JAMA (1986) 256(14):1899-903. doi:10.1001/jama.1986.03380140069024

32. Wennerholm UB, Holm B, Mattsby-Baltzer I, Nielsen T, Platz-Christensen J, Sundell G, et al. Fetal fibronectin, endotoxin, bacterial vaginosis and cervical length as predictors of preterm birth and neonatal morbidity in twin pregnancies 1970. Br J Obstet Gynaecol (1997) 104(12):1398-404. doi:10.111 1/j.1471-0528.1997.tb11010.x

33. Gratacos E, Figueras F, Barranco M, Vila J, Cararach V, Alonso PL, et al. Spontaneous recovery of bacterial vaginosis during pregnancy is not associated with an improved perinatal outcome 1971. Acta Obstet Gynecol Scand (1998) 77(1):37-40. doi:10.1080/00016349808565808

34. Holst E, Goffeng AR, Andersch B. Bacterial vaginosis and vaginal microorganisms in idiopathic premature labor and association with pregnancy outcome 1972. J Clin Microbiol (1994) 32(1):176-86.

35. Eschenbach DA, Gravett MG, Chen KC, Hoyme UB, Holmes KK. Bacterial vaginosis during pregnancy. An association with prematurity and postpartum complications 1973. Scand J Urol Nephrol Suppl (1984) 86:213-22.

36. McDonald HM, O'Loughlin JA, Jolley P, Vigneswaran R, McDonald PJ. Prenatal microbiological risk factors associated with preterm birth. BJOG (1992) 99(3):190-6. doi:10.1111/j.1471-0528.1992.tb14497.x

37. Nugent RP, Krohn MA, Hillier SL. Reliability of diagnosing bacterial vaginosis is improved by a standardized method of gram stain interpretation. J Clin Microbiol (1991) 29(2):297-301.

38. Lamont RF, Sobel JD, Akins RA, Hassan SS, Chaiworapongsa T, Kusanovic JP, et al. The vaginal microbiome: new information about genital tract flora using molecular based techniques. BJOG (2011) 118(5):533-49. doi:10.1111/j.1471-0528.2010.02840.x

39. Fredricks DN, Fiedler TL, Marrazzo JM. Molecular identification of bacteria associated with bacterial vaginosis. N Engl J Med (2005) 353(18):1899-911. doi:10.1056/NEJMoa043802

40. Srinivasan S, Hoffman NG, Morgan MT, Matsen FA, Fiedler TL, Hall RW, et al. Bacterial communities in women with bacterial vaginosis: high resolution phylogenetic analyses reveal relationships of microbiota to clinical criteria. PLoS One (2012) 7(6):e37818. doi:10.1371/journal.pone.0037818

41. AJEaPJ F. Prevalence of bacterial vaginosis: 2001-2004 National Health and Nutrition Examination Survey data. Obstet Gynecol (2007) 109(1):114-20. doi:10.1097/01.AOG.0000247627.84791.91

42. Hay PE, Morgan DJ, Ison CA, Bhide SA, Romney M, McKenzie P, et al. A longitudinal study of bacterial vaginosis during pregnancy. BJOG (1994) 101(12):1048-53. doi:10.1111/j.1471-0528.1994.tb13580.x

43. Lamont RF, Nhan-Chang CL, Sobel JD, Workowski K, Conde-Agudelo A, Romero R. Treatment of abnormal vaginal flora in early pregnancy with clindamycin for the prevention of spontaneous preterm birth: a systematic review and metaanalysis. Am J Obstet Gynecol (2011) 205(3):177-90. doi:10.1016/j.ajog.2011.03.047

44. Rosenstein IJ, Morgan DJ, Lamont RF, Sheehan M, Dore CJ, Hay PE, et al. Effect of intravaginal clindamycin cream on pregnancy outcome and on abnormal vaginal microbial flora of pregnant women. Infect Dis Obstet Gynecol (2000) 8(3-4):158-65. doi:10.1155/S1064744900000211

45. Duff P, Lee ML, Hillier SL, Herd LM, Krohn MA, Eschenbach DA. Amoxicillin treatment of bacterial vaginosis during pregnancy. Obstet Gynecol (1991) 77(3):431-5.

46. Morales WJ, Schorr S, Albritton J. Effect of metronidazole in patients with preterm birth in preceding pregnancy and bacterial vaginosis: a placebo-controlled, double-blind study. Am J Obstet Gynecol (1994) 171(2):345-7. doi:10.1016/S0002-9378(94)70033-8

47. Hauth JC, Goldenberg RL, Andrews WW, DuBard MB, Copper RL. Reduced incidence of preterm delivery with metronidazole and erythromycin in women with bacterial vaginosis. $N$ Engl J Med (1995) 333(26):1732-6. doi:10.1056/NEJM199512283332603

48. Joesoef MR, Hillier SL, Wiknjosastro G, Sumampouw H, Linnan M, Norojono W, et al. Intravaginal clindamycin treatment for bacterial vaginosis: effects on preterm delivery and low birth weight. Am J Obstet Gynecol (1995) 173(5):1527-31. doi:10.1016/0002-9378(95)90644-4

49. McGregor JA, French JI, Parker R, Draper D, Patterson E, Jones W, et al. Prevention of premature birth by screening and treatment for common genital tract infections: results of a prospective controlled evaluation. Am J Obstet Gynecol (1995) 173(1):157-67. doi:10.1016/0002-9378(95)90184-1

50. McDonald HM, O'Loughlin JA, Vigneswaran R, Jolley PT, Harvey JA, Bof A, et al. Impact of metronidazole therapy on preterm birth in women with bacterial vaginosis flora (Gardnerella vaginalis): a randomised, placebo controlled trial. BJOG (1997) 104(12):1391-7. doi:10.1111/j.1471-0528.1997.tb11009.x

51. Vermeulen GM, Bruinse HW. Prophylactic administration of clindamycin $2 \%$ vaginal cream to reduce the incidence of spontaneous preterm birth in women with an increased recurrence risk: a randomised placebo-controlled double-blind trial. BJOG (1999) 106(7):652-7. doi:10.1111/j.1471-0528.1999. tb08363.x

52. Carey JC, Klebanoff MA, Hauth JC, Hillier SL, Thom EA, Ernest JM, et al. Metronidazole to prevent preterm delivery in pregnant women with asymptomatic bacterial vaginosis. National Institute of Child Health and Human Development Network of Maternal-Fetal Medicine Units. N Engl J Med (2000) 342(8):534-40. doi:10.1056/NEJM200002243420802

53. Kurkinen-Raty M, Vuopala S, Koskela M, Kekki M, Kurki T, Paavonen $\mathrm{J}$, et al. A randomised controlled trial of vaginal clindamycin for early pregnancy bacterial vaginosis. BJOG (2000) 107(11):1427-32. doi:10.111 1/j.1471-0528.2000.tb11660.x

54. Kekki M, Kurki T, Pelkonen J, Kurkinen-Raty M, Cacciatore B, Paavonen J. Vaginal clindamycin in preventing preterm birth and peripartal infections in asymptomatic women with bacterial vaginosis: a randomized, controlled trial. Obstet Gynecol (2001) 97(5 Pt 1):643-8. doi:10.1016/S0029-7844(01)01321-7

55. Klebanoff MA, Carey JC, Hauth JC, Hillier SL, Nugent RP, Thom EA, et al. Failure of metronidazole to prevent preterm delivery among pregnant women with asymptomatic Trichomonas vaginalis infection. $N$ Engl J Med (2001) 345(7):487-93. doi:10.1056/NEJMoa003329

56. Porter K, Rambo D, Jazayeri M, Prien S. Prospective randomized trial of once versus twice a day metronidazole vaginal in obstetrical identified with bacterial vaginosis. Am J Obstet Gynecol (2001) 184(1 Pt 2):S166-S.

57. Odendaal HJ, Popov I, Schoeman J, Smith M, Grove D. Preterm labour - is bacterial vaginosis involved? S Afr Med J (2002) 92(3):231-4.

58. Guaschino S, Ricci E, Franchi M, Frate GD, Tibaldi C, Santo DD, et al. Treatment of asymptomatic bacterial vaginosis to prevent pre-term delivery: a randomised trial. Eur J Obstet Gynecol Reprod Biol (2003) 110(2):149-52. doi:10.1016/S0301-2115(03)00107-6

59. Lamont RF, Duncan SL, Mandal D, Bassett P. Intravaginal clindamycin to reduce preterm birth in women with abnormal genital tract flora. Obstet Gynecol (2003) 101(3):516-22. doi:10.1016/S0029-7844(02)03054-5

60. Ugwumadu A, Manyonda I, Reid F, Hay P. Effect of early oral clindamycin on late miscarriage and preterm delivery in asymptomatic women with abnormal vaginal flora and bacterial vaginosis: a randomised controlled trial. Lancet (2003) 361(9362):983-8. doi:10.1016/S0140-6736(03)12823-1

61. Kiss H, Petricevic L, Husslein P. Prospective randomised controlled trial of an infection screening programme to reduce the rate of preterm delivery. BMJ (2004) 329(7462):371. doi:10.1136/bmj.38169.519653.EB

62. Larsson PG, Fahraeus L, Carlsson B, Jakobsson T, Forsum U. Late miscarriage and preterm birth after treatment with clindamycin: a randomised consent design study according to Zelen. BJOG (2006) 113(6):629-37. doi:10.1111/j.1471-0528.2006.01114.x

63. McDonald HM, Brocklehurst P, Gordon A. Antibiotics for treating bacterial vaginosis in pregnancy. Cochrane Database Syst Rev (2007) 1:CD000262.

64. Swadpanich U, Lumbiganon P, Prasertcharoensook W, Laopaiboon M. Antenatal lower genital tract infection screening and treatment programs for preventing preterm delivery. Cochrane Database Syst Rev (2008) 2:CD006178. doi:10.1002/14651858.CD006178.pub2

65. Hutzal CE, Boyle EM, Kenyon SL, Nash JV, Winsor S, Taylor DJ, et al. Use of antibiotics for the treatment of preterm parturition and prevention of neonatal morbidity: a metaanalysis. Am J Obstet Gynecol (2008) 199(6):620-8. doi:10.1016/j.ajog.2008.07.008 
66. Simcox R, Sin WT, Seed PT, Briley A, Shennan AH. Prophylactic antibiotics for the prevention of preterm birth in women at risk: a meta-analysis. Aust N Z J Obstet Gynaecol (2007) 47(5):368-77. doi:10.1111/j.1479-828X.2007.00759.x

67. Varma R, Gupta JK. Antibiotic treatment of bacterial vaginosis in pregnancy: multiple meta-analyses and dilemmas in interpretation. Eur J Obstet Gynecol Reprod Biol (2006) 124(1):10-4. doi:10.1016/j.ejogrb.2005.07.015

68. Okun N, Gronau KA, Hannah ME. Antibiotics for bacterial vaginosis or Trichomonas vaginalis in pregnancy: a systematic review. Obstet Gynecol (2005) 105(4):857-68. doi:10.1097/01.AOG.0000157108.32059.8f

69. Riggs MA, Klebanoff MA. Treatment of vaginal infections to prevent preterm birth: a meta-analysis. Clin Obstet Gynecol (2004) 47(4):796-807. doi:10.1097/01.grf.0000141450.61310.81

70. Leitich H, Brunbauer M, Bodner-Adler B, Kaider A, Egarter C, Husslein P. Antibiotic treatment of bacterial vaginosis in pregnancy: a meta-analysis. Am J Obstet Gynecol (2003) 188(3):752-8. doi:10.1067/mob.2003.167

71. Koumans EH, Markowitz LE, Hogan V. Indications for therapy and treatment recommendations for bacterial vaginosis in nonpregnant and pregnant women: a synthesis of data. Clin Infect Dis (2002) 35(Suppl 2):S152-72. doi:10.1086/342103

72. Guise JM, Mahon SM, Aickin M, Helfand M, Peipert JF, Westhoff C. Screening for bacterial vaginosis in pregnancy. Am J Prev Med (2001) 20(Suppl 3):62-72. doi:10.1016/S0749-3797(01)00256-2

73. Klein LL, Gibbs RS. Use of microbial cultures and antibiotics in the prevention of infection-associated preterm birth. Am J Obstet Gynecol (2004) 190(6):1493-502. doi:10.1016/j.ajog.2004.03.014

74. Brocklehurst P, Gordon A, Heatley E, Milan SJ. Antibiotics for treating bacterial vaginosis in pregnancy. Cochrane Database Syst Rev (2013) 1:Cd000262. doi:10.1002/14651858.CD000262.pub4

75. Lamont RF, Khan KS, Beattie B, Cabero RL, Di Renzo GC, Dudenhausen JW, et al. The quality of nifedipine studies used to assess tocolytic efficacy: a systematic review. J Perinat Med (2005) 33(4):287-95.

76. Workowski KA, Berman SM. Sexually transmitted diseases treatment guidelines, 2006. MMWR Recomm Rep (2006) 55(RR-11):1-94.

77. Esterly NB, Furey NL, Flanagan LE. The effect of antimicrobial agents on leukocyte chemotaxis. J Invest Dermatol (1978) 70(1):51-5. doi:10.1111/15231747.ep12543487

78. Hand WL, Hand DL, King-Thompson NL. Antibiotic inhibition of the respiratory burst response in human polymorphonuclear leukocytes. Antimicrob Agents Chemother (1990) 34(5):863-70. doi:10.1128/AAC.34.5.863

79. Konno S, Asano K, Kurokawa M, Ikeda K, Okamoto K, Adachi M. Antiasthmatic activity of a macrolide antibiotic, roxithromycin: analysis of possible mechanisms in vitro and in vivo. Int Arch Allergy Immunol (1994) 105(3):308-16. doi:10.1159/000236773

80. Mikasa K, Kita E, Sawaki M, Kunimatsu M, Hamada K, Konishi M, et al. The anti-inflammatory effect of erythromycin in zymosan-induced peritonitis of mice. J Antimicrob Chemother (1992) 30(3):339-48. doi:10.1093/jac/30.3.339

81. Takeshita K, Yamagishi I, Harada M, Otomo S, Nakagawa T, Mizushima Y. Immunological and anti-inflammatory effects of clarithromycin: inhibition of interleukin 1 production of murine peritoneal macrophages. Drugs Exp Clin Res (1989) 15(11-12):527-33.

82. Barry AL, Thornsberry C, Jones RN. In vitro activity of a new macrolide, A-56268, compared with that of roxithromycin, erythromycin, and clindamycin. Antimicrob Agents Chemother (1987) 31(2):343-5. doi:10.1128/ AAC. 31.2.343

83. Young RA, Gonzalez JP, Sorkin EM. Roxithromycin. A review of its antibacterial activity, pharmacokinetic properties and clinical efficacy. Drugs (1989) 37(1):8-41. doi:10.2165/00003495-198937010-00002

84. Hillier SL, Holmes KK. Bacterial vaginosis. In: Holmes KK, Markowitz LE, Spellacy W, Wiggins R, editors. Sexually Transmitted Diseases. New York, NY: McGraw-Hill (1990). p. 547-50.

85. Spiegel CA, Eschenbach DA, Amsel R, Holmes KK. Curved anaerobic bacteria in bacterial (nonspecific) vaginosis and their response to antimicrobial therapy. J Infect Dis (1983) 148(5):817-22. doi:10.1093/infdis/148.5.817

86. Spiegel CA. Susceptibility of Mobiluncus species to 23 antimicrobial agents and 15 other compounds. Antimicrob Agents Chemother (1987) 31(2):249-52. doi:10.1128/AAC.31.2.249

87. Taylor-Robinson D, Lamont RF. Mycoplasmas in pregnancy. BJOG (2011) 118(2):164-74. doi:10.1111/j.1471-0528.2010.02766.x
88. Goldstein EJ, Citron DM, Merriam CV, Warren YA, Tyrrell KL, Fernandez HT. In vitro activities of garenoxacin (BMS 284756) against 108 clinical isolates of Gardnerella vaginalis. Antimicrob Agents Chemother (2002) 46(12):3995-6. doi:10.1128/AAC.46.12.3995-3996.2002

89. Xiao JC, Xie LF, Fang SL, Gao MY, Zhu Y, Song LY, et al. Symbiosis of Mycoplasma hominis in Trichomonas vaginalis may link metronidazole resistance in vitro. Parasitol Res (2006) 100(1):123-30. doi:10.1007/ s00436-006-0215-y

90. De Backer E, Dubreuil L, Brauman M, Acar J, Vaneechoutte M. In vitro activity of secnidazole against Atopobium vaginae, an anaerobic pathogen involved in bacterial vaginosis. Clin Microbiol Infect (2009) 16:470-2. doi:10.1111/j.1469-0691.2009.02852.x

91. Ferris MJ, Masztal A, Aldridge KE, Fortenberry JD, Fidel PL Jr, Martin $\mathrm{DH}$. Association of Atopobium vaginae, a recently described metronidazole resistant anaerobe, with bacterial vaginosis. BMC Infect Dis (2004) 4:5 doi:10.1186/1471-2334-4-5

92. Bradshaw CS, Morton AN, Hocking J, Garland SM, Morris MB, Moss LM, et al. High recurrence rates of bacterial vaginosis over the course of 12 months after oral metronidazole therapy and factors associated with recurrence. $J$ Infect Dis (2006) 193(11):1478-86. doi:10.1086/503780

93. Krausse R, Schubert S. In-vitro activities of tetracyclines, macrolides, fluoroquinolones and clindamycin against Mycoplasma hominis and Ureaplasma ssp. isolated in Germany over 20 years. Clin Microbiol Infect (2010) 16(11):1649-55. doi:10.1111/j.1469-0691.2009.03155.x

94. Blackwell AL. Vaginal bacterial phaginosis? Sex Transm Infect (1999) 75(5):352-3. doi:10.1136/sti.75.5.352

95. Viniker DA. Hypothesis on the role of sub-clinical bacteria of the endometrium (bacteria endometrialis) in gynaecological and obstetric enigmas. Hum Reprod Update (1999) 5(4):373-85. doi:10.1093/ humupd/5.4.373

96. Morency AM, Bujold E. The effect of second-trimester antibiotic therapy on the rate of preterm birth. J Obstet Gynaecol Can (2007) 29(1):35-44.

97. Andrews WW, Goldenberg RL, Hauth JC, Cliver SP, Copper R, Conner M. Interconceptional antibiotics to prevent spontaneous preterm birth: a randomized clinical trial. Am J Obstet Gynecol (2006) 194(3):617-23. doi:10.1016/j.ajog.2005.11.049

98. van den Broek NR, White SA, Goodall M, Ntonya C, Kayira E, Kafulafula G, et al. The APPLe study: a randomized, community-based, placebo-controlled trial of azithromycin for the prevention of preterm birth, with meta-analysis. PLoS Med (2009) 6(12):e1000191. doi:10.1371/journal.pmed.1000191

99. Luntamo M, Kulmala T, Mbewe B, Cheung YB, Maleta K, Ashorn P. Effect of repeated treatment of pregnant women with sulfadoxine-pyrimethamine and azithromycin on preterm delivery in Malawi: a randomized controlled trial. Am J Trop Med Hygeine (2010) 83(6):1212-20. doi:10.4269/ ajtmh.2010.10-0264

100. Keelan JA, Kemp MW, Payne MS, Johnson D, Stock SJ, Saito M, et al. Maternal administration of solithromycin, a new, potent, broad-spectrum fluoroketolide antibiotic, achieves fetal and intra-amniotic antimicrobial protection in a pregnant sheep model. Antimicrob Agents Chemother (2014) 58(1):447-54. doi:10.1128/AAC.01743-13

101. Miura Y, Payne MS, Keelan JA, Noe A, Carter S, Watts R, et al. Maternal intravenous treatment with either azithromycin or solithromycin clears Ureaplasma parvum from the amniotic fluid in an ovine model of intrauterine infection. Antimicrob Agents Chemother (2014) 58(9):5413-20. doi:10.1128/ AAC.03187-14

102. Bakketeig LS, Hoffman HJ, Harley EE. The tendency to repeat gestational age and birth weight in successive births. Am J Obstet Gynecol (1979) 135(8):1086-103.

103. Hoffman HJ, Bakketeig LS. Risk factors associated with the occurrence of preterm birth. Clin Obstet Gynecol (1984) 27(3):539-52. doi:10.1097/00003081-198409000-00004

104. Shennan A, Crawshaw S, Briley A, Hawken J, Seed P, Jones G, et al. A randomised controlled trial of metronidazole for the prevention of preterm birth in women positive for cervicovaginal fetal fibronectin: the PREMET Study. BJOG (2006) 113(1):65-74. doi:10.1111/j.1471-0528.2005.00788.x

105. Lamont RF, Dragovic B. A randomised controlled trial of metronidazole for the prevention of preterm birth in women positive for cervicovaginal fetal fibronectin: the PREMET Study by Shennan et al. BJOG (2006) 113(7):850-1. doi:10.1111/j.1471-0528.2006.00958.x 
106. Alfirevic A, Alfirevic Z, Pirmohamed M. Pharmacogenetics in reproductive and perinatal medicine. Pharmacogenomics (2010) 11(1):65-79. doi:10.2217/ pgs.09.153

107. Berg TG, Philpot KL, Welsh MS, Sanger WG, Smith CV. Ureaplasma/Mycoplasma-infected amniotic fluid: pregnancy outcome in treated and nontreated patients. J Perinatol (1999) 19(4):275-7. doi:10.1038/ sj.jp. 7200185

108. Cassell GH, Davis RO, Waites KB, Brown MB, Marriott PA, Stagno S, et al. Isolation of Mycoplasma hominis and Ureaplasma urealyticum from amniotic fluid at 16-20 weeks of gestation: potential effect on outcome of pregnancy. Sex Trans Dis (1983) 10(Suppl 4):294-302.

109. Gerber S, Vial Y, Hohlfeld P, Witkin SS. Detection of Ureaplasma urealyticum in second-trimester amniotic fluid by polymerase chain reaction correlates with subsequent preterm labor and delivery. J Infect Dis (2003) 187(3):518-21. doi: $10.1086 / 368205$

110. Gray DJ, Robinson HB, Malone J, Thomson RB Jr. Adverse outcome in pregnancy following amniotic fluid isolation of Ureaplasma urealyticum. Prenat Diagn (1992) 12(2):111-7.

111. Horowitz S, Mazor M, Romero R, Horowitz J, Glezerman M. Infection of the amniotic cavity with Ureaplasma urealyticum in the midtrimester of pregnancy. J Reprod Med (1995) 40(5):375-9.

112. Nguyen DP, Gerber S, Hohlfeld P, Sandrine G, Witkin SS. Mycoplasma hominis in mid-trimester amniotic fluid: relation to pregnancy outcome. J Perinat Med (2004) 32(4):323-6.

113. Perni SC, Vardhana S, Korneeva I, Tuttle SL, Paraskevas LR, Chasen ST, et al. Mycoplasma hominis and Ureaplasma urealyticum in midtrimester amniotic fluid: association with amniotic fluid cytokine levels and pregnancy outcome. Am J Obstet Gynecol (2004) 191(4):1382-6. doi:10.1016/j. ajog.2004.05.070

114. Lamont RF. Infection and preterm labour. BJOG (1998) 105(12):1339-40. doi $: 10.1111 / j .1471-0528.1998 . t b 10030 . x$

115. Lamont RF. Antibiotics for the prevention of preterm birth. N Engl J Med (2000) 342(8):581-3. doi:10.1056/NEJM200002243420810

116. Lamont RF. Association between cerebral palsy and erythromycin. Lancet (2009) 373(9657):26. doi:10.1016/S0140-6736(08)61947-9

117. Mason MR, Adrinkra PE, Lamont RF. Prophylactic administration of clindamycin $2 \%$ vaginal cream to reduce the incidence of spontaneous preterm birth in women with an increased risk: a randomised placebo-controlled double-blind trial. BJOG (2000) 107(2):295-6. doi:10.1111/j.1471-0528.2000. tb11707.x

118. Lamont RF. The maternal fetal medicine network trial. Am J Obstet Gynecol (2005) 193(1):306-7. doi:10.1016/j.ajog.2005.01.080

119. Lamont RF, Taylor-Robinson D, Hay PE. Antibiotics for adverse outcomes of pregnancy. Lancet (2001) 358(9294):1728-9. doi:10.1016/ S0140-6736(01)06749-6

120. Lamont RF. Antibiotics used in women at risk of preterm birth. Am J Obstet Gynecol (2008) 199(6):583-4. doi:10.1016/j.ajog.2008.07.007

121. Macones GA, Parry S, Elkousy M, Clothier B, Ural SH, Strauss JF III. A polymorphism in the promoter region of TNF and bacterial vaginosis: preliminary evidence of gene-environment interaction in the etiology of spontaneous preterm birth. Am J Obstet Gynecol (2004) 190(6):1504-8. doi:10.1016/j.ajog.2004.01.001

122. Ng PY, Ireland DJ, Keelan JA. Drugs to block cytokine signaling for the prevention and treatment of inflammation-induced preterm birth. Front Immunol (2015) 6:166. doi:10.3389/fimmu.2015.00166

123. Ireland DJ, Kemp MW, Miura Y, Saito M, Newnham JP, Keelan JA. Intraamniotic pharmacological blockade of inflammatory signalling pathways in an ovine chorioamnionitis model. Mol Hum Reprod (2015) 21(5):479-89. doi:10.1093/molehr/gav005

124. Grigsby PL, Novy MJ, Sadowsky DW, Morgan TK, Long M, Acosta E, et al. Maternal azithromycin therapy for Ureaplasma intraamniotic infection delays preterm delivery and reduces fetal lung injury in a primate model. Am J Obstet Gynecol (2012) 207(6):e1-14. doi:10.1016/j.ajog.2012.10.871

125. Gravett MG, Adams KM, Sadowsky DW, Grosvenor AR, Witkin SS, Axthelm $\mathrm{MK}$, et al. Immunomodulators plus antibiotics delay preterm delivery after experimental intraamniotic infection in a nonhuman primate model. Am J Obstet Gynecol (2007) 197(5):e1-8. doi:10.1016/j.ajog.2007.03.064
126. Lamont RF, Jones BM, Mandal D, Hay PE, Sheehan M. The efficacy of vaginal clindamycin for the treatment of abnormal genital tract flora in pregnancy. InfectDis Obstet Gynecol(2003) 11(4):181-9. doi:10.1080/10647440300025519

127. Lamont RF, Taylor-Robinson D, Bassett P. Rescreening for abnormal vaginal flora in pregnancy and re-treating with clindamycin vaginal cream significantly increases cure and improvement rates. Int J STD AIDS (2012) 23(8):565-9. doi:10.1258/ijsa.2011.011229

128. Hay PE, Taylor-Robinson D, Lamont RF. Preterm premature rupture of membranes. Lancet (1996) 347(8995):203. doi:10.1016/S0140-6736(96)90390-6

129. Lamont RF. Preterm labour prevention clinics. BJOG (2014) 121(10): 1317-8. doi:10.1111/1471-0528.12731

130. Lamont RF. Changes in vaginal flora after $2 \%$ clindamycin vaginal cream in women at high risk of preterm birth. BJOG (2003) 110:788-9. doi:10.1111/j.1471-0528.2003.01040.x

131. Kenyon S, Pike K, Jones DR, Brocklehurst P, Marlow N, Salt A, et al. Childhood outcomes after prescription of antibiotics to pregnant women with spontaneous preterm labour: 7-year follow-up of the ORACLE II trial. Lancet (2008) 372(9646):1319-27. doi:10.1016/S0140-6736(08)61203-9

132. Kenyon SL, Taylor DJ, Tarnow-Mordi W. Broad-spectrum antibiotics for spontaneous preterm labour: the ORACLE II randomised trial. ORACLE Collaborative Group. Lancet (2001) 357(9261):989-94. doi:10.1016/ S0140-6736(00)04234-3

133. Cassell GH, Crouse DT, Waites KB, Rudd PT, Davis JK. Does Ureaplasma urealyticum cause respiratory disease in newborns? Pediatr Infect Dis J (1988) 7(8):535-41.

134. Taylor-Robinson D, Morgan DJ, Sheehan M, Rosenstein IJ, Lamont RF. Relation between Gram-stain and clinical criteria for diagnosing bacterial vaginosis with special reference to Gram grade II evaluation. Int J STD AIDS (2003) 14(1):6-10. doi:10.1258/095646203321043183

135. Lamont HF, Blogg HJ, Lamont RF. Safety of antimicrobial treatment during pregnancy: a current review of resistance, immunomodulation and teratogenicity. Expert Opin Drug Saf (2014) 13(12):1569-81. doi:10.1517/147403 38.2014.939580

136. Broe A, Pottegard A, Lamont R, Jorgensen J, Damkier P. Increasing use of antibiotics in pregnancy during the period 2000-2010: prevalence, timing, category, and demographics. BJOG (2014) 121(8):988-96. doi:10.1111/1471-0528.12806

137. The Pew Charitable Trusts. GAIN: How a New Law is Stimulating the Development of Antibiotics (2013) [2014 Apr 21]. Available from: http://www. pewhealth.org/other-resource/gain-how-a-new-law-is-stimulating-the-development-of-antibiotics-85899518481\#sthash.mPWCEg9C.dpuf

138. Thomas M, Price D. Prenatal antibiotic exposure and subsequent atopy. Am J Respir Crit Care Med (2003) 167(11):1578. doi:10.1164/ajrccm.167.11.956

139. McKeever TM, Lewis SA, Smith C, Hubbard R. The importance of prenatal exposures on the development of allergic disease: a birth cohort study using the West Midlands General Practice Database. Am J Respir Crit Care Med (2002) 166(6):827-32. doi:10.1164/rccm.200202-158OC

140. Tsakok T, McKeever TM, Yeo L, Flohr C. Does early life exposure to antibiotics increase the risk of eczema? A systematic review. Br J Dermatol (2013) 169(5):983-91. doi:10.1111/bjd.12476

141. Stensballe LG, Simonsen J, Jensen SM, Bonnelykke K, Bisgaard H. Use of antibiotics during pregnancy increases the risk of asthma in early childhood. J Pediatr (2013) 162(4):832-38.e3. doi:10.1016/j.jpeds.2012.09.049

142. Lyndrup J, Lamont RF. The choice of a tocolytic for the treatment of preterm labor: a critical evaluation of nifedipine versus atosiban. Expert Opin Investig Drugs (2007) 16(6):843-53. doi:10.1517/13543784.16.6.843

Conflict of Interest Statement: The author declares that the research was conducted in the absence of any commercial or financial relationships that could be construed as a potential conflict of interest.

Copyright $\odot 2015$ Lamont. This is an open-access article distributed under the terms of the Creative Commons Attribution License (CC BY). The use, distribution or reproduction in other forums is permitted, provided the original author(s) or licensor are credited and that the original publication in this journal is cited, in accordance with accepted academic practice. No use, distribution or reproduction is permitted which does not comply with these terms. 